staff were seeing the number expected. It was also observed that non-smokers seemed firm in their intention not to smoke. Such intentions may be misleading. Only $6 \%$ of children think they will be regular smokers when they leave school, ${ }^{2}$ but if current rates reported in the general household survey continue as many as $37 \%$ will be regular smokers by their early $20 \mathrm{~s}$. At these rates one in three teenagers stating an intention not to smoke is likely to become a regular smoker within the next few years. There is clearly much to be done to strengthen and reinforce the early intention not to become a smoker, and this study suggests that most adolescents would welcome such an initiative from general practice.

Working party: David Simpson, John Davies, Jennifer Charlton, Julian Tudor Hart, Mary Tudor Hart, Andrew Haines, Godfrey Fowler, Paula Morgan, Martin Jarvis, Joy Townsend, Helen Wilkes.

We thank Dr David Davidson, Dr Michael Cripwell, Dr John Davies, Dr Julian Tudor Hart, Dr Susan Hunt, Jennifer Charlton, Mary Tudor Hart, and Paula Morgan for taking part in the study; Dr Paul Roderick and Dr James Connelly for helpful comments; and Dr Tom Meade for advice and support.

1 Office of Population Censuses and Surveys. Cigarette smoking 1972-1988. London: HMSO, 1990. (SS 90/1.)

2 Lader D, Matheson J. Smoking among secondary school children in 1990. London: HMSO, 1991.

3 Catford JC, Nutbeam D, Woolaway M. Effectiveness and cost benefits of smoking education. Community Medicine 1984;6:264-72.

4 Doll R. Age distribution of cancer: implications for models of carcinogenesis. fournal of the Royal Statistical Society (A) 1971;134:133-6.

5 Townsend JL. Smoking and lung cancer: a cohort data study of men and Townsend JL. Smoking and lung cancer: a cohort data study of men and
women in England and Wales 1935-1970. Fournal of the Royal Statistical women in England and Wales 1935

6 Balding J. Young people in 1988. Exeter: HEA Schools Health Education Unit, Exeter University, 1989

7 Macfarlane A, McPherson A, McPherson K, Ahmed L. Teenagers and their health. Arch Dis Child 1987;62:1125-9.
8 Murray M, Swann AO, Clarke G. Long term effect of a school based antismoking programme. J Epidemiol Community Health 1984;38:247-52.

9 Cleary PD, Hitchcock JL, Semmers N, Flinchbaugh L, Pinney J. Adolescen smoking: research and health policy. Cambridge, Massachusetts: Institute for the Study of Smoking Behaviour and Policy, 1986.

10 Jamrozik K, Vessey M, Fowler G, Wald N, Parker G, Van Vanakis H. Controlled trial of three different antismoking interventions in general practice. BMf 1984;288:1499-503.

11 Richmond R, Webster I. Evaluation of general practitioners' use of a smoking intervention programme. Int $\mathcal{f}$ Epidemiol 1985;14:396-401.

12 Russell MAH, Wilson C, Taylor C, Baker CD. Effective general practitioners' advice against smoking. $B M \mathcal{F}$ 1979;ii:231-5.

3 Townsend JL. Economic and health consequences of reduced smoking. In Williams A, ed. Health and economics. London: Macmillan, 1987:139-61.

4 Williams A. Economics of coronary artery bypass grafting. BMF 1985;291: 326-9.

15 Health Education Authority. A smoker's guide to giving up. London: HEA 1987.

16 Cancer Research Campaign/Tacade. Packing it in. London: CRC/Tacade, 1988

17 McNeill AD, Jarvis MJ, West R, Russell MAH, Bryant A. Saliva cotinine as an indicator of cigarette smoking in adolescents. $\mathrm{Br} \mathcal{J}$ Addict 1987;82: $1355-60$.

18 Cutler SF, Wallace PG, Haines AP. Assessing alcohol consumption in general practice patients - a comparison between questionnaire and interview (findings of the Medical Research Council's General Practice Research Framework study on lifestyle and health). Alcohol Alcohol 1988;23:441-50.

19 Donovan CF, McCarthy S. Is there a place for adolescent screening in general practice? Health Trends 1988;2:20;64.

20 Jarvis MJ, Russel MAH, Feyerabend C, Eiser J, Morgan M, Gammage P, Gray E. Passive exposure to tobacco smoke: saliva cotinine concentrations in a representative population sample of non-smoking schoolchildren. $B M$ 1985;291:927-9.

21 Janerich DT, Thompson WD, Varela LR, Greenwald P, Chorost P, Tucci C. Lung cancer and exposure to tobacco smoke in the household. $N$ Engl 7 Med 1990;323:632-6.

22 Green $M$, Jucha $E$, Luz $Y$. Blood pressure in smokers and non smokers: epidemiological findings. Am Heart $f$ 1986;111:932-40.

23 St George IM, Williams S, Stanton W, Silva PA. Smoking and blood pressure in 15 year olds in Dunedin in New Zealand. BMJ 1991;302:89-90.

24 Kershaw CR. Passive smoking, potential atopy and asthma in the first five years. $7 R$ Soc Med 1987,80:683-8.

25 Croft $P$, Hannaford PC. Risk factors for acute myocardial infarction in women: evidence from the Royal College of General Practitioners' oral contraceptive evidence from the Royal College

26 Wallace PG, Haines AP, Brennan PJ. Are GPs doing enough to promote healthy lifestyle? Findings of the MRC General Practice Research Framework study on lifestyle and health. $B M \mathcal{F} 1987 ; 294: 940-2$.

(Accepted 23 fuly 1991 )

\title{
Elderly and younger patients selected to undergo coronary angiography
}

\author{
A T Elder, T R D Shaw, C M Turnbull, I R Starkey
}

\section{Abstract}

Objective-To establish and compare the characteristics of older ( $\geqslant 70$ years) and younger patients with chest pain selected to undergo coronary angiography and by analysis of their subsequent management to assess the value of coronary angiography for older patients with chest pain.

Design-Retrospective analysis of clinical case notes and coronary angiography reports.

Setting-Cardiology department with referral population of one million in an Edinburgh hospital.

Patients - 134 consecutive patients with chest pain aged 70 years or over investigated by coronary angiography between 1978 and 1988; 134 randomly selected patients aged under 70 investigated over the same period.

Main outcome measures-Clinical and angiographic features at time of angiography and management after angiography.

Results-Older patients represented a small, but increasing, proportion of those investigated. Older patients had more severe symptoms at the time of angiography, were taking more antianginal drugs, and had had their symptoms for longer than younger patients. At angiography more older patients had triple vessel coronary disease, left main stem stenosis, or left ventricular impairment. After angiography similar proportions of older and younger patients underwent coronary artery surgery, with more elderly patients requiring urgent operation; although operative mortality was higher for elderly patients, symptomatic benefit was similar to that in younger patients.

Conclusions-Older patients with angina selected to undergo coronary angiography and subsequent coronary surgery have more severe symptoms and underlying cardiac disease. Earlier referral and investigation might yield a population with lower operative risk. Selection of patients for coronary angiography and coronary artery surgery should be based on the potential for benefit and should avoid "agism."

\section{Introduction}

The number of elderly people in the United Kingdom has risen progressively and there has been an associated increase in the prevalence of age related conditions such as angina pectoris. Although cardiology departments have consequently experienced an increase in the number of elderly patients referred for investigation of coronary artery disease, such patients still represent only a small proportion of the total number undergoing coronary angiography. To assess the value of coronary angiography in elderly patients with angina we reviewed the angiographic findings and clinical features and outcome of patients aged 70 years or more who had coronary angiography during 1978-88
Correspondence to:

Dr Elder.

BMf 1991;303:950-3 
and compared the results with those of younger patients investigated during the same period.

\section{Patients and methods}

The cardiac laboratory record books for the 11 year period 1978-88 were reviewed. During this period 134 patients age 70 years or over (median 72.8 (range $70-85$ ) years) had undergone coronary angiography for investigation of chest pain. Patients with valve or congenital heart disease, cardiomyopathy, and previous bypass surgery were not included. A total of 134 patients aged under 70 years (median $51 \cdot 7$ (range 3268) years) undergoing coronary angiography were selected from the same source by a random method that allowed the annual number of patients in each group to be matched. The case notes and angiographic data of all 268 patients were then reviewed, analysed, and compared and additional follow up data were obtained from general practitioners when necessary.

Significant stenosis was defined as a reduction of the luminal diameter of a coronary artery of $50 \%$ or more. Left ventricular function was graded as good, moderate, or poor by left ventricular angiography.

Means were recorded with their standard errors, medians with their $95 \%$ confidence intervals. The comparison of proportions between the two groups was based on the $\chi^{2}$ test, with the test for trend where appropriate, and calculation of the associated $\mathrm{p}$ value A p value $<0.05$ was considered significant. Additionally, the $95 \%$ confidence intervals for the difference between proportions, when expressed as percentages, are shown.

\section{Results}

Table I shows the annual number of patients aged $\geqslant 70$ years undergoing coronary angiography during 1978-88. The number of elderly patients having

TABLE II -Clinical characteristics of patients undergoing coronary angiography

\begin{tabular}{|c|c|c|c|c|c|c|}
\hline Clinical feature & $\begin{array}{l}\text { No }(\%) \text { of } \\
\text { patients aged } \\
\geqslant 70 \text { years } \\
(n=134)\end{array}$ & $\begin{array}{l}\text { No }(\%) \text { of } \\
\text { patients aged } \\
<70 \text { years } \\
(n=134)\end{array}$ & $\begin{array}{c}95 \% \mathrm{CI} \text { for } \\
\text { difference } \\
\text { between } \\
\text { proportions }\end{array}$ & $\chi^{2}$ & df & $\begin{array}{c}\mathrm{p} \\
\text { Value }\end{array}$ \\
\hline Men:women & $(56): 59(44)$ & $103(77): 31(23)$ & $10 \%$ to $32 \%$ & $13 \cdot 1$ & 1 & $<0.001$ \\
\hline History of hypertension & $30(22)$ & $32(24)$ & $-7 \%$ to $3 \%$ & $0 \cdot 1$ & 1 & 0.77 \\
\hline Current cigarette smoking & $27(20)$ & $59(44)$ & $14 \%$ to $35 \%$ & $17 \cdot 5$ & 1 & $<0.001$ \\
\hline Obesity (body mass index $>25 \mathrm{~kg} / \mathrm{m}^{2}$ ) & $52(39)$ & $88(66)$ & $15 \%$ to $38 \%$ & $19 \cdot 4$ & 1 & $<0.001$ \\
\hline Diabetes mellitus & $9(7)$ & $4(3)$ & $0 \%$ to $9 \%$ & $2 \cdot 0$ & 1 & $0 \cdot 15$ \\
\hline History of cerebrovascular disease & $15(11)$ & $8(6)$ & $0 \%$ to $10 \%$ & $2 \cdot 3$ & 1 & $0 \cdot 13$ \\
\hline Histo & 20 & $5(4)$ & $4 \%$ to $18 \%$ & $9 \cdot 9$ & 1 & 0.002 \\
\hline History of myocardial infarction & $75(56)$ & $56(42)$ & $2 \%$ to $26 \%$ & $5 \cdot 4$ & 1 & 0.02 \\
\hline \multicolumn{7}{|l|}{ History of coronary artery disease of more } \\
\hline than five years & $51(38)$ & $22(16)$ & $12 \%$ to $32 \%$ & $15 \cdot 8$ & 1 & 0.001 \\
\hline \multicolumn{7}{|l|}{ New York Heart Association symptom classt: } \\
\hline $\begin{array}{r}I(n=13) \\
I(n=88)\end{array}$ & $1(8)$ & $12(92)$ & & & & \\
\hline II $(n=88)$ & $28(32)$ & $60(68)$ & & & & \\
\hline III $(n=108)$ & $61(56)$ & $47(44)$ & & & & \\
\hline IV $(n=59)$ & $44(74)$ & $15(26)$ & & $52 \cdot 7$ & 3 & $<0.001^{\star}$ * \\
\hline \multicolumn{7}{|l|}{ No of antianginal drugst: } \\
\hline $0(n=36)$ & $16(44)$ & $20(56)$ & & & & \\
\hline $1(n=63)$ & $19(30)$ & $44(70)$ & & & & \\
\hline $2(n=105)$ & $53(50)$ & $52(50)$ & & & & \\
\hline $3(n=64)$ & $46(72)$ & $18(28)$ & & $14 \cdot 2$ & 3 & $0 \cdot 002^{\star}$ \\
\hline
\end{tabular}

$\mathrm{CI}=$ Confidence interval. $\quad{ }^{\star} \chi^{2}$ test for trend. $\quad$ Percentages are of all patients $(\geqslant 70$ or $<70$ years $)$.

TABLE III - Angiographic findings in patients undergoing coronary angiography

\begin{tabular}{|c|c|c|c|c|c|c|}
\hline Angiographic findings & $\begin{array}{l}\text { No }(\%) \text { of } \\
\text { patients aged } \\
\geqslant 70 \text { years } \\
(n=134)\end{array}$ & $\begin{array}{l}\text { No }(\%) \text { of } \\
\text { patients aged } \\
<70 \text { years } \\
(n=134)\end{array}$ & $\begin{array}{l}95 \% \mathrm{CI} \text { for } \\
\text { difference } \\
\text { between } \\
\text { proportions }\end{array}$ & $\chi^{2}$ & df & $\begin{array}{c}p \\
\text { Value }\end{array}$ \\
\hline \multicolumn{7}{|l|}{ Coronary artery disease: } \\
\hline None $(n=27)$ & $9(33)$ & $18(67)$ & & & & \\
\hline Single vessel $(n=55)$ & $17(31)$ & $38(69)$ & & & & \\
\hline Two vessel $(n=68)$ & $26(38)$ & $42(62)$ & & & & \\
\hline Three vessel $(n=118)$ & $82(69)$ & $36(31)$ & & $25 \cdot 5$ & 3 & $<0.001^{\star}$ \\
\hline Left mainstem stenosis & $28(21)$ & $5(4)$ & $10 \%$ to $24 \%$ & $18 \cdot 3$ & 1 & $<0.001$ \\
\hline \multicolumn{7}{|l|}{ Left ventricular function: } \\
\hline Good & $82(61)$ & $101(75)$ & & & & \\
\hline Moderate or poor & $52(39)$ & $33(25)$ & $3 \%$ to $25 \%$ & $6 \cdot 2$ & 1 & 0.01 \\
\hline
\end{tabular}

$\mathrm{CI}=$ Confidence interval . coronary angiography during the final five years of this period was 12 times greater than in the first five years; because the total number of coronary angiograms performed rose from 150 in 1978 to 720 in 1988, after patients with associated valve or congenital heart disease had been excluded, the contribution of elderly patients to the total coronary angiogram caseload increased by under four times, from $1 \cdot 3 \%$ to $4 \cdot 6 \%$. Patients can be referred to our department either directly from local general practitioners or from general physicians in our hospital or several other referring hospitals, so it is not possible to determine how many elderly individuals with persistent chest discomfort were not referred or were referred but not investigated. As the prevalence of angina in elderly people is $10 \%,{ }^{\prime}$ and about $10 \%$ of our referral population is aged 70 or over, we believe that those investigated during this period represent a small minority of our elderly population with angina. The referral population of approximately one million remained stable during the period studied and the waiting list for non-urgent coronary angiography never exceeded three months. The waiting list for elective coronary surgery was, however, up to a year.

\section{CLINICAL CHARACTERISTICS}

Table II shows the clinical characteristics of the elderly and younger patients. Although we reviewed a relatively small proportion of younger patients, their characteristics are comparable to those of younger patients undergoing angiography in larger North American series ${ }^{2}$ and we therefore believe are representative of our younger patients in general. There was a noticeable difference in the sex ratio of the two groups, with 59 women in the elderly group (44\%) and 31 in the younger group (23\%). Fewer of the elderly patients were smokers and fewer were obese (body mass index $>25 \mathrm{~kg} / \mathrm{m}^{2}$ ). A similar number in each group had a history of hypertension. Peripheral vascular disease (defined as a history of intermittent claudication) and previous myocardial infarction (defined by standard electrocardiographic criteria or documented at hospital admission) were significantly more common in the elderly patients, but cerebrovascular disease (defined as a history of transient ischaemic attacks or stroke) was not. The elderly patients had had angina for much longer before angiography (median 36 (95\% confidence interval 30 to 96) months, compared with the younger patients (12 (9 to 18) months; $95 \%$ confidence interval for difference 6 to 30 months). A substantially greater proportion of the elderly patients were in the more severe New York Heart Association symptom classes III or IV $(105(79 \%) v 62(46 \%)$ of younger patients; $95 \%$ confidence interval for difference $20 \%$ to $42 \%$ ) and more elderly patients had been hospitalised for their symptoms at the time of angiography $(35(26 \%) v$ $12(12 \%) ; 5 \%$ to $23 \%)$. Elderly patients had received more intensive antianginal drug treatment than younger patients: $46(34 \%)$ were receiving treatment with three classes of antianginal drug compared with $18(13 \%)$ in the younger group (12\% to $32 \%)$.

\section{ANGIOGRAPHIC FINDINGS}

Table III shows the results of coronary angiography for the two groups. Nine elderly patients $(7 \%)$ and 18 younger patients (13\%) had normal coronary angiograms. The patients aged $\geqslant 70$ years were more likely to have three vessel coronary artery disease $(82(61 \%) v$ $36(27 \%) ; 23 \%$ to $45 \%)$ and the finding of a mainstem stenosis was much commoner in the elderly patients $(28(21 \%)$ v $5(4 \%) ; 10 \%$ to $24 \%)$. The left ventricular function of elderly patients was more often impaired at left ventricular angiography (52 (39\%) v $33(25 \%) ; 3 \%$ to $25 \%$ ). 


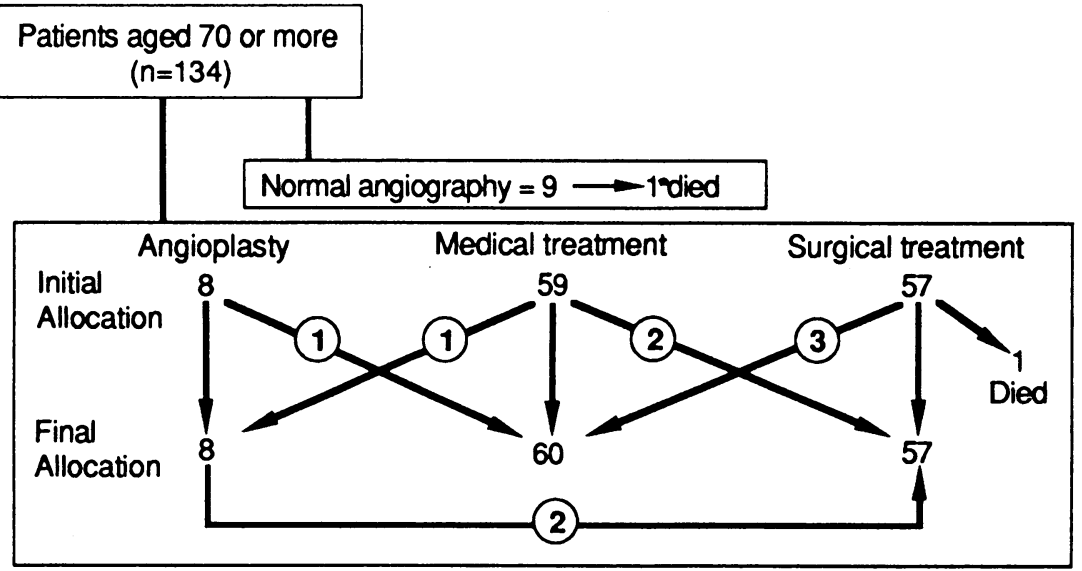

Patients aged under 70 years

$(n=134)$
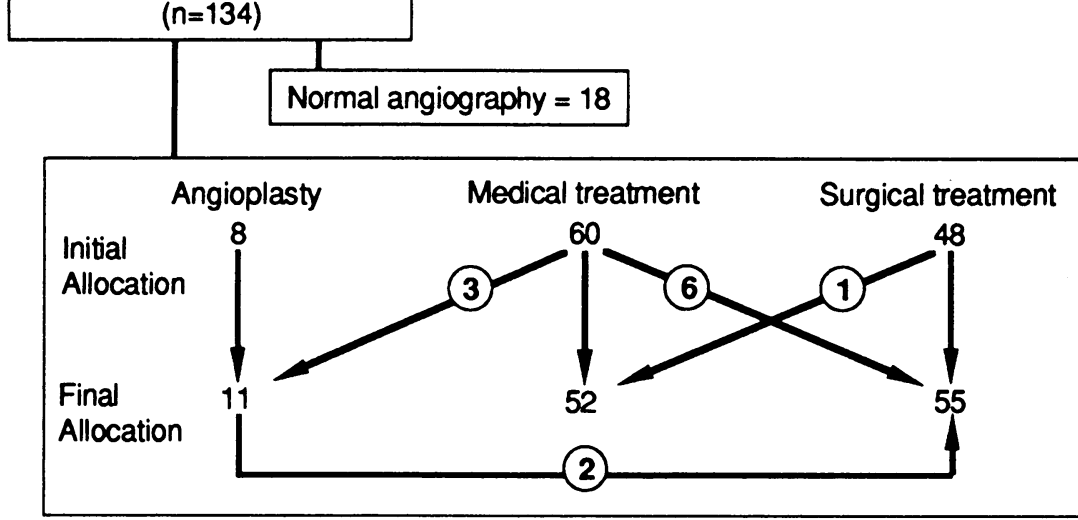

Initial and final allocations to treatment for older and younger patients after coronary angiography
Complications at coronary angiography were infrequent, even in the elderly group. One patient, a 70 year old man with a history of cerebrovascular disease, suffered a cerebrovascular accident during the procedure and died 36 hours later. No other death, myocardial infarction, or other non-transient complication occurred in either group.

\section{CLINICAL OUTCOME AFTER ANGIOGRAPHY}

After angiography patients were discussed at a meeting of physicians and surgeons. Some patients were allocated to surgical treatment or angioplasty. Some with very diffuse coronary disease or severe left ventricular impairment, or both, were judged to be technically unattractive for cardiac surgery and were allocated to continued or intensified medical treatment. Those considered to have a stable pattern of coronary disease were initially allocated to intensified medical treatment when feasible. If medical treatment failed to produce satisfactory control of symptoms some patients were then reallocated to treatment by angioplasty or surgery. The figure shows the initial and final treatment allocations for the elderly and younger groups.

Eight of the older and 11 of the younger patients underwent angioplasty. A total of 57 of the 134 elderly patients $(43 \%)$ underwent operation compared with 55 $(41 \%)$ of the younger group. The 112 operations were performed by seven different surgeons operating within one unit over the study period. In all, $44(77 \%)$ of the elderly and $28(51 \%)$ of the younger surgical patients had triple vessel disease. Main stem stenosis was present in $19(34 \%)$ of the elderly and five $(9 \%)$ of the younger patients, and impaired left ventricular function was present in $19(34 \%)$ and $10(18 \%)$ respectively. Urgent coronary bypass surgery (defined as within one week of angiography) was required by 15 of the 57 elderly surgical patients (23\%) and by two of the 55 younger patients $(4 \%)$.

The survival at 30 days and one year after elective surgery was $95 \%$ (two deaths) and $93 \%$ (one further death) for the 42 elderly patients and $100 \%$ and $98 \%$ (one death) for the 53 younger patients. The survival after urgent cardiac surgery at both 30 days and one year was $60 \%$ (six deaths) for the 15 elderly patients and $100 \%$ for the two younger patients. Two of the six elderly patients who died after urgent operation had non-standard surgery. One had a punch ostiotomy for an isolated main stem ostial stenosis and one had additional repair of a post infarction ventricular septal defect. No younger patient had any alternative or additional procedure.

Table IV shows the preoperative and postoperative symptom classification and medical treatment of patients undergoing surgery. The elderly and younger surgical patients experienced equivalent improvement in symptoms and reduction in use of antianginal drugs.

TABLE IV-Symptoms and drug treatment before and one year after coronary artery surgery

\begin{tabular}{|c|c|c|c|c|}
\hline & \multicolumn{2}{|c|}{$\begin{array}{c}\text { Patients aged } \\
\begin{array}{c}\geqslant 70 \text { years } \\
(n=57)\end{array}\end{array}$} & \multicolumn{2}{|c|}{$\begin{array}{c}\text { Patients aged } \\
<70 \text { years } \\
(\mathbf{n}=55)\end{array}$} \\
\hline & $\begin{array}{c}\text { Before } \\
\text { operation }\end{array}$ & $\begin{array}{l}1 \text { Year after } \\
\text { operation` }\end{array}$ & $\begin{array}{c}\text { Before } \\
\text { operation }\end{array}$ & $\begin{array}{l}1 \text { Year after } \\
\text { operation }\end{array}$ \\
\hline \multicolumn{5}{|c|}{ New York Heart Association symptom class: } \\
\hline I & & 29 & & 38 \\
\hline II & 8 & 11 & 18 & 10 \\
\hline III & 27 & 7 & 31 & 6 \\
\hline IV & 22 & & 6 & \\
\hline Dead & & 9 & & 1 \\
\hline \multicolumn{5}{|c|}{ No of antianginal drugs: } \\
\hline 0 & 3 & 28 & 2 & 29 \\
\hline 1 & 6 & 13 & 17 & 20 \\
\hline 2 & 22 & 4 & 25 & 4 \\
\hline 3 & 26 & 2 & 11 & 1 \\
\hline
\end{tabular}

*One patient in this group was lost to follow up.

\section{Discussion}

In 1990 about $11 \%$ of the United Kingdom population was aged over 70 years and $40 \%$ was aged $30-70 .^{3}$ As the prevalence of angina pectoris in elderly people is approximately $10 \%,{ }^{1}$ compared with only $0 \cdot 6-1 \cdot 5 \%$ in the younger population ${ }^{4}$ it can be estimated that most people who suffer from angina in the United Kingdom are elderly. Nevertheless, substantially fewer elderly patients with angina undergo investigation by coronary angiography or treatment by coronary artery surgery. In this study patients aged over 70 represented only $5 \%$ of all patients having coronary angiography in 1988 . Similarly, in the North American coronary artery surgery study only $3 \%$ of patients undergoing coronary arteriography were aged over 70 years, ${ }^{5}$ but the current rate of $15-20 \%$ for coronary bypass surgery in patients aged over 70 in some American surgical series ${ }^{6}$ suggests that the angiography rate may also have risen.

Selecting elderly patients for angiography and cardiac surgery is undoubtedly more complex than selecting younger patients. Older patients may be more prepared to reduce their physical activity to live within the limits imposed by their cardiac symptoms, and for some (but not all) the prospect of an improved prognosis is not important. In addition, some elderly patients have other medical problems which may compromise their capacity to survive or to recover from major surgery.

In our study, over an 11 year period those elderly patients who were selected for angiography differed substantially from younger patients. Elderly patients had more severe angina, were more likely to be hospitalised with unstable angina, were taking more antianginal drugs, and had been treated medically for a longer period; this suggests that quite different referral and selection policies for coronary angiography were applied to older and younger patients with angina, although we cannot at present determine whether this 
occurred at the level of patient, general practitioner, general physician, or cardiologist. At angiography elderly patients had more severe and extensive coronary disease and had developed greater myocardial impairment, and as these factors, the severity of symptoms, and the need for urgent surgery have all been identified as predictors of surgical mortality these patients have an intrinsically higher operative risk, even before the effect of age is considered. We believe, therefore, that earlier referral and investigation of elderly patients who may be candidates for cardiac surgery - at a stage when their symptoms are limiting but not yet unstable-would yield a group for whom surgery could provide important symptomatic benefit, but at lower risk.

The implementation of such a policy would, in the context of our changing demography, place increased stress on already seriously overextended cardiac diagnostic facilities and staffing. ${ }^{7}$ Additionally, the provision of cardiac surgery within the NHS has tended to be restricted, and most cardiac surgery units have long waiting lists, often extending to over a year for nonurgent cases. In such circumstances of limited resources there is a danger that the medical needs of elderly patients may be looked on less favourably than those of younger patients, a prejudice termed agism. ${ }^{8}$ Although this method of discriminating between patients competing for a finite resource may be convenient, it is rarely rational, and we are not aware of any public consensus regarding prejudicial selection on the grounds of age as a means of distributing treatment within the NHS. If finite resources require some patients to receive less than optimal treatment then this should be enacted by excluding those with less potential for benefit. A 70 year old patient with limiting angina and an average life expectancy of 10-14 years may often have such potential overlooked.

The successful outcome of coronary artery surgery in elderly patients with stable symptoms who are found at angiography to have coronary disease suitable for elective surgery supports the view that it is appropriate for an elderly patient with limiting angina to be referred for coronary angiography and, when necessary, added to the cardiac surgical waiting list. Only in this way can the necessary level of funding for cardiac surgery be identified.

1 Kennedy RD, Andrews GR, Caird FI. Ischaemic heart disease in the elderly. Br Heart F 1977;39:1121-7.

2 Gersh BJ, Kronmal RA, Frye RL, Schaff HV, Ryan TJ, Gosselin AJ, et al. Coronary arteriography and coronary artery bypass surgery: morbidity and mortality in patients aged 65 years or older. Circulation 1983;67:483-91. 3 Office of Population Censuses and Surveys. Population Trends 1990;62:43.

4 Cannon PJ, Connel PA Stockley IH, Garner ST, Hampton JR. Prevalence of angina as assessed by a survey of prescriptions of nitrates. Lancet 1988;i:
$979-81$.

5 Mock MB. Prognosis of coronary heart disease in the elderly patient: the CASS experience. In: Coodley EL, ed. Geriatric heart disease. Littleton, Massachusetts: PSG Publishing, EL, ed. Geria

6 Christakis GT, Ivanov J, Weisel RD, Birnbaum PL, David TE, Salerno TA, et al. The changing pattern of coronary artery bypass surgery. Circulation 1989;80(suppl I):151-61

7 Chamberlain D, Alderslade R. Can rationing of cardiological services be rational? Br Heart f 1990;64:219-22.

8 Currie CT. Doctors and ageism. Br Med f 1988;295:1586.

(Accepted 23 fuly 1991)
University Department of Medicine and Pharmacology, Section of Pharmacology,and Therapeutics, Royal Hallamshire Hospital, Sheffield S10 2JF

E E Ramsay, FRCP consultant physician and professor

W W Yeo, MRCP, senior registrar and lecturer P R Jackson, MRCP, consultant physician and senior lecture

Correspondence to: Professor Ramsay.

BMF 1991;303:953-7
L E Ramsay, W W Weo, P R Jackson

Abstract

Objective-To evaluate the long term efficacy of diets in lowering serum cholesterol concentration.

Design-Descriptive overview of 16 published controlled trials of six months' duration or longer.

Setting-Trials had been conducted in hospital clinics (6), industry (3), mental hospitals or institutions (3), and in general populations (4).

Patients - Trials had been conducted in high risk subjects (.5), in unselected healthy subjects $(6)$, or for secondary prevention in patients with coronary heart disease (5). Women were included in only four trials.

Interventions-Diets equivalent to the step 1 diet were employed in eight trials, with individual intervention by dietitians (3) or occupational physicians (2) or with population advice (3). Intensive diets which were more rigorous than the step 2 diet were employed in eight trials.

Main outcome measures-Net change in serum total cholesterol concentration in subjects receiving treatment with diet compared with values in control subjects after six months to $\mathbf{1 0}$ years.

Results-In five trials with the step 1 diet as individual intervention the net reduction in serum cholesterol concentration ranged from $0 \%$ to $4.0 \%$ over six months to six years. In trials with population education reductions in cholesterol concentrations were $0 \cdot 6-2 \cdot 0 \%$ over five to 10 years. When population and individual dietary advice were combined changes in cholesterol concentration ranged from a fall of $2 \cdot 1 \%$ to a rise of $1.0 \%$ over four to 10 years. Diets more intensive than the step 2 diet reduced serum cholesterol concentration by $13 \%$ over five years in selected high risk men in the population; by $6 \cdot 5$ $15 \cdot 1 \%$ over two to five years in hospital outpatients; and by $12 \cdot 8-15 \cdot 5 \%$ over one to four and a half years in patients in institutions.

Conclusions - The response to a step 1 diet is too small to have any value in the clinical management of adults with serum cholesterol concentrations above $6.5 \mathrm{mmol} / \mathrm{l}$. Current guidelines recommend screening of serum cholesterol concentration in healthy subjects, followed by treatment with a step 1 diet. The guidelines should be reviewed to provide a more realistic estimate of the effect of a step 1 diet and of the likely need for lipid lowering drugs.

\section{Introduction}

Every $1 \%$ reduction in serum cholesterol concentration reduces the risk of coronary events by about 1$2 \% .^{1}$ Guidelines for managing patients with high cholesterol concentrations concur that diet is of prime importance in management, ${ }^{2 \cdot-7}$ and advocate as initial treatment the step $1,{ }^{6}$ or general lipid lowering diet (box). ${ }^{8}$ If this proves insufficient the more intensive step 2 diet is advised (box). ${ }^{6}$ These recommendations are based on epidemiological considerations ${ }^{9}$ and short term experiments. ${ }^{10}$ Estimates of cholesterol reduction by the step 1 diet range from $10 \%$ to $25 \%,{ }^{68}$ but there are suggestions that it may be insufficiently effective. ${ }^{11-13}$ In Britain about $40 \%$ of adults have serum cholesterol concentrations in the moderate to high risk category and are therefore considered to need clinical care ${ }^{14-16}$ and a standing medical advisory committee has emphasised that cost effective management 